\title{
CONSIDERAÇÕES SOBRE DIAGRAMAS COMO FERRAMENTAS DE REPRESENTAÇÃO EM LÓGICA
}

\author{
REMARKS ABOUT DIAGRAMS AS LOGIC REPRESENTATION TOOLS
}

Félix Flores Pinheiro*

\section{RESUMO}

O presente artigo possui por objetivo discorrer sobre como diagramas representam em contextos lógicos. Com a recente revisão do status dos métodos diagramáticos de representação em ciências formais, o presente artigo oferece uma abordagem em torno das características representacionais que distinguem diagramas de métodos puramente sentenciais. Focando nos critérios distintivos oferecidos pela literatura da área, oferta-se uma reflexão sobre o papel que diagramas desempenham enquanto ferramentas representativas em contextos lógicos, contrastando-os com ferramentas linguísticas. Argumenta-se que diagramas representam através de "semelhanças estruturais", resultando em uma preservação de algumas das características relacionais do que está sendo representado. Métodos diagramáticos utilizam relações espaciais para "espelhar" as relações presentes no conjunto de objetos que visam representar, enquanto métodos linguísticos alocam todas essas em dispositivos representacionais simbólicos. Por conta disso, representações diagramáticas obtêm os lucros e os prejuízos de utilizar características espaciais enquanto meio representacional. Todavia, como diferentes métodos diagramáticos administram essa utilização de forma distinta, tais virtudes e prejuízos também são variantes entre métodos diagramáticos.

PALAVRAS-CHAVE: Diagramas. Semiótica. Filosofia da Lógica. Representação diagramática. Lógica diagramática.

\begin{abstract}
The present article aims to discuss how diagrams represent in logical contexts. With the recent review of the status of diagrammatic representational methods in formal sciences, the present paper offers an approach about the representational characteristics that distinguish diagrams from purely sentential methods. I focus on some distinctive criteria offered by the literature, and offer an investigation about the role of diagrams as representative tools in logical contexts, in contrast with linguistic representative ways. I argue that diagrams represent through "structural similarities"; which results in a structural preservation of some relations between the objects in target. Diagrammatic methods use spatial relations to mirror some relational aspects present in the set of objects that aim to represent, while purely linguistics representations have symbols for all this. Thus, diagrammatic representations derive its benefits and drawbacks through the way they manage this characteristic. However, since diagrammatic methods treats the spatial background in different ways, the benefits and drawbacks varies from method to method.
\end{abstract}

KEYWORDS: Diagrams. Semiotics. Philosophy of Logic. Diagram Representation. Diagrammatic logic.

\footnotetext{
* Mestre em filosofia pela UFSM. Doutorando em filosofia pela UFSC. feliks.sm@gmail.com.
} 


\section{INTRODUÇÃO}

O presente artigo investiga em que medida representações diagramáticas em contextos lógicos se diferenciam de representações sentenciais (que recorrem exclusivamente a fórmulas) para o mesmo contexto, ponderando sobre as consequências representacionais da especificidade das primeiras. ${ }^{1}$ Passado o século de ouro do desenvolvimento das ciências formais, encontramos nos resquícios dos projetos que se popularizaram decorrências filosóficas interessantes. Um desses resquícios é constituído pela negligência do papel que figuras e diagramas poderiam compor em lógica e matemática. Recentemente, filósofos dedicados às ciências formais questionaram os propósitos e os acertos da ideia de que figuras e diagramas deveriam ser excluídas de certos procedimentos da lógica e da matemática, em especial que elas não poderiam compor parte em uma demonstração legítima.

Ocorre que, como apresentado em outras pesquisas que realizamos (2015), embora haja um vasto uso de ferramentas diagramáticas (bem como de instrumentos físicos, como o ábaco) na história da matemática, a partir do século XIX há um evidente contexto de exclusão desses elementos em prol do fortalecimento de uma visão da lógica e da matemática que permeia os escritos de Frege, os desenvolvimentos formalistas do projeto de Hilbert, a abordagem bourbakista da matemática, dentre outras. É com base em concepções oriundas dessa visão que se popularizaram, por exemplo, as noções de que a matemática, em especial a geometria, é "um voo cego" e que não fala sobre figuras em sentido concreto, mas sobre entidades abstratas. Como mostra Seoane (2012), o pensamento de que representações com apelo visual compunham aspectos errôneos incontornáveis fora tão dominante que tornou-se, inclusive, incomum encontrar qualquer menção ou justificativa explícita dessa ideia, restandonos apenas afirmações isoladas em diversas obras que indicam essa ideia e reafirmam esse diagnóstico.

Para além dessa abordagem intrínseca às ciências formais, Mancosu (2008) mostra também que o mesmo contexto teve consequências para a filosofia da lógica e da matemática, as quais tiveram foco nos aspectos ontológicos, epistêmicos e semânticos, deixando estudos sobre a prática matemática em segundo plano. Não à toa, os trabalhos recentes que retomam essas questões diagnosticam problemas em torno das confusões entre os aspectos teóricos e

\footnotetext{
${ }^{1}$ Representações diagramáticas são pensadas na literatura da área como métodos diagramáticos que auxiliam inferências através de mistos entre sentenças/fórmulas e diagramas; em oposição às representações sentenciais que utilizam apenas sentenças ou fórmulas, por esse motivo, métodos diagramáticos têm sido referidos na literatura da área como sendo "heterogêneos".
} 
práticos oriundos daquelas abordagens, como por exemplo a análise efetuada por Sundholm (1993).

Que esse cenário proporcionou o maior desenvolvimento das ciências formais na história da humanidade é fato absolutamente inegável. Todavia, dada a pluralidade das concepções filosóficas envolvidas nas crenças subjacentes aos variados projetos que resultaram nesses frutos, há na literatura filosófica um crescente movimento que questiona várias dessas concepções, reavaliando o status dos elementos excluídos por elas, como por exemplo dos elementos visuais e das provas assistidas por computadores. Através da denominação "raciocínio visual" (visual thinking), o tema da utilização de figuras e elementos visuais em geometria retomou destaque em filosofia da matemática. Impulsionado pela revisão de obras clássicas que utilizam elementos diagramáticos e visuais, como, por exemplo, Os elementos de Euclides, autores como Mancosu (2005), Lassalle Casanave, Schultz e Vaz (2009) e Azzouni (2013) retomam os motivos pelos quais a utilização dessas ferramentas fora vista como inadequada, questionando por quais razões elas ofereceriam menor rigor e clareza nas demonstrações matemáticas; por quais motivos essas ferramentas possuem características com potencial errôneo incontornável. Apesar de a vertente matemática desse assunto ser mais destacada, uma reflexão semelhante tem ocorrido sobre a utilização de diagramas em lógica, principalmente através de autores como Barwise e Etchemendy (1996) e da filósofa Shin (1994). É nesse último contexto que o presente artigo se insere, possuindo por objetivo analisar em que medida estamos justificados em dizer que ferramentas diagramáticas proporcionam menor rigor e clareza para as abordagens em lógica. Ainda assim, serão realizadas breves menções aos trabalhos que vêm sendo desenvolvidos sobre o uso de figuras em geometria, tanto para acentuar as diferenças entre ambos os temas, quanto para esclarecer características representacionais em comum.

A fim de analisar essa questão, o texto que segue oferta uma reflexão de cunho semiótico sobre as características distintivas entre meios de representação, as semelhanças e diferenças entre utilizar um meio diagramático e um meio puramente sentencial (cuja expressão é dada exclusivamente através das fórmulas de um sistema). Cabe notar que tratamentos semióticos, grosso modo, partem da ideia de que os sujeitos significam "objetos" através de signos e que esse panorama forma várias relações entre "objeto representante", "sujeito" e "objeto representado" que podem ser exploradas. Dentre essas relações, duas possuem maior enfoque frente ao propósito do presente artigo: a) como os signos se relacionam com aquilo que representam e b) quais as consequências epistêmicas da utilização 
de distintos meios de representação para os sujeitos em termos pragmáticos, cognitivos e psicológicos. $^{2}$ A abordagem que segue visa o tratamento da utilização de ferramentas diagramáticas em contextos lógicos com enfoque nessa primeira via de análise, ou seja, nas semelhanças e diferenças entre utilizar distintos conjuntos de signos em suas relações com aquilo que eles representam, das relações de tipo a). Uma investigação acerca de b) pode ser encontrada em nosso trabalho posterior (2015), a qual nos permite esclarecer no que consiste claramente essa distinção em diversas partes do estudo aqui realizado. Essa distinção é importante porque diversos autores da literatura sobre o tema têm desenvolvido ambos vieses em suas abordagens.

No texto que segue, nossas considerações sobre como diagramas atuam enquanto ferramentas de representação em lógica estão organizadas em três seções. Inicialmente, características distintivas são apresentadas e analisadas, partindo de aspectos mais triviais, como a utilização de figuras, para características mais substanciais. Após, aborda-se o que significa exatamente utilizar um meio diagramático de representação e como isso poderia ser menos rigoroso, possuindo aspectos acidentais. Por fim, as consequências envolvidas nessa prática são exploradas, questionando se há alguma característica que legitime ou justifique a crença de que diagramas são meios menos rigorosos.

\section{ASPECTOS TRIVIAIS E A NOÇÃO DE “PRESERVAÇÃO DE ESTRUTURA"}

A ideia de que diagramas não podem compor parte em demonstrações legítimas pode estar justificada se houver características inertes a essas ferramentas que impeçam ou comprometam esse procedimento. Tais características devem estar no ponto de desencontro entre maneiras diagramáticas e não diagramáticas, visto que demonstrações que utilizam apenas fórmulas, recorrendo às representações de estilo puramente sentencial, são legítimas. Nesse sentido, o ponto de partida para essa discussão tem sido buscar elementos distintivos entre meios diagramáticos e sentenciais de representação. A literatura da área tem investigado esse assunto visando encontrar, principalmente, uma única característica distintiva; todavia,

\footnotetext{
${ }^{2}$ Teorias semióticas consagradas na história da filosofia, como por exemplo a exposta por Peirce, trabalham com uma relação tripla entre significantes e significados. Todavia, para os propósitos do presente artigo, basta notar que estaremos distinguindo estre esses dois tipos de abordagens de acordo com o foco dos seus estudos.
} 
não há qualquer razão para supormos que haja apenas uma característica, ao invés de um conjunto de elementos. ${ }^{3}$

Uma primeira ideia, que apesar de trivial merece ser mencionada, diz respeito à utilização de figuras. Poder-se-ia pensar que métodos diagramáticos se distinguem de métodos sentenciais porque os primeiros utilizam figuras como objetos de representação, enquanto os segundos utilizam apenas caracteres. Todavia, utilizar apenas letras, apenas figuras geométricas ou outro tipo de escrita para representar os objetos não oferece, por si só, uma diferença relevante entre representações sentenciais e diagramáticas. Essa ideia é explorada por Shin (1994); no último capítulo do livro The Logical Status of Diagrams, a autora mostra maneiras de representar uma relação espacial através de um diagrama que utiliza palavras e através de sentenças formais que utilizam figuras geométricas como símbolos. Por exemplo, podemos representar o mesmo conteúdo da sentença “Ana está sentada entre João e Maria" com um diagrama que respeita a relação espacial utilizando símbolos, inclusive geométricos, mas também as próprias palavras que denotam os nomes dos indivíduos deixando como elemento tácito o respeito à ordenação espacial da escrita, como: João - Ana - Maria.

Todavia, para os contextos geométricos a incorreção dessa ideia pode ser menos evidente, visto que em geral as representações diagramáticas nesse caso envolvem figuras. Nesses contextos poder-se-ia exigir que as representações possuam algum grau de semelhança com aquilo que representam, como a figura de um triângulo e o conceito de triângulo. Na literatura da área, essa ideia aparece nas afirmações de que métodos diagramáticos e sentencias são distintos por conta de um critério de semelhança. Uma das bases para a afirmação de tal critério encontra-se em partes dos estudos sobre os signos efetuados por C. S. Peirce $(1839$ - 1914). Tendo em vista que a "mais fundamental divisão dos signos" (PEIRCE CP 2.275 apud LEGRIS, 2013, p. 53, tradução nossa) realizada por Peirce distingue entre índices, ícones e símbolos, os diagramas foram entendidos como um tipo de signo "verdadeiramente icônico, naturalmente análogo àquilo que está representado, e não uma criação de convenções" (PEIRCE, 4.368, apud MANCOSU, 2012, p. 8). Prima facie, tal caracterização distancia diagramas e figuras geométricas de representações simbólicas, convencionais, como sentenças e palavras, aproximando-as de representações que exploram

\footnotetext{
${ }^{3}$ A ideia de que há um conjunto de elementos, inclusive, absorve melhor a distinção entre as relações de tipo a) e b) supramencionadas, pois é mais provável que haja características distintivas em ambos os âmbitos, que essas estejam relacionadas entre si e formem um escopo de elementos representacionais distinto entre diagramas e sentenças.
} 
semelhanças, como retratos. Todavia, supor que há uma semelhança pictórica, de nível parecido com o que ocorre em fotografias, entre diagramas em lógica e figuras geométricas em geometria é implausível visto que os objetos representados são conceitos abstratos. Como expõe Mancosu (2012), o tipo de semelhança que poderia haver entre um objeto físico e visível e uma entidade abstrata, invisível, não recai em aspectos pictóricos; afinal, o desenho de um triângulo não é uma "fotografia" do conceito de triângulo. Cabe notar que Peirce possui uma enorme quantidade de escritos sobre o assunto, de modo com que é difícil atribuir qualquer pensamento como sendo uma afirmação categórica do autor, em especial sobre o tema dos diagramas, visto que o próprio conceito de "diagrama" possui um papel central na obra do autor. Para uma melhor compreensão desse assunto, pode-se ver o artigo de Franco e Borges (2016), no qual as autoras exploram as distinções peircianas com maior profundidade, analisando os distintos tipos de ícones e os relacionando ao conceito de "diagrama".

Ainda assim, o mesmo que acontece com a sugestão de um critério de semelhança pictórica, também ocorre quando levamos em conta a ideia de que diagramas representam utilizando "menos convenções" do que sentenças, mas precisamos ser cautelosos ao afirmar isso, visto que há muitas convenções envolvidas na construção e na representação dos sistemas lógicos. Por exemplo, a simples necessidade de esclarecermos o contexto segundo o qual o diagrama deve ser interpretado evidencia a presença dos elementos convencionais envolvidos. O diagrama apresentado na Figura 1, que ilustra uma circunferência B dentro de um círculo limitado por uma circunferência A, é compatível com diversas interpretações.

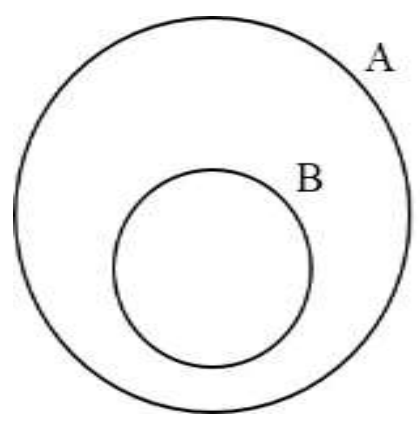

Figura 1. Exemplo de Diagrama com distintas interpretações

$\mathrm{Na}$ literatura da área, a ideia de que diagramas utilizam menos convenções é afirmada por Shin (1994) e foi questionada por Giardino (2013). ${ }^{4}$ Para essa última autora, diagramas

\footnotetext{
${ }^{4}$ É importante ressaltar que, como apresentamos em outro trabalho (2015), as ideias de Shin (1994) acerca da utilização de menos convenções em ferramentas diagramáticas faz muito mais sentido quando a ênfase está nas
} 
devem ser considerados no interior de um contexto de uso, de modo com que figuras fechadas, relações espaciais e até mesmo diagramas completos podem representar uma variedade de circunstâncias. Por exemplo, o diagrama apresentado na Figura 1 pode estar inserido no contexto da geometria euclidiana, da geometria cartesiana, em diferentes sistemas de representação em lógica, como nos diagramas de Euler ou nos diagramas de Peirce. Em cada caso, o papel desempenhado pela estrutura é distinto, bem como os significados das suas partes.

Tanto o critério de utilização de convenções, quanto o de semelhança pictórica, fracassam frente a constatação de que diagramas estão sempre inseridos em contextos de representação. Nesse sentido, como afirma Mancosu (2012, p. 9) "devemos abandonar a relação de semelhança pictórica e buscar algo mais apropriado". Seguindo novamente os escritos de Peirce, esse 'algo mais apropriado' tem sido entendido como a capacidade dos signos icônicos representarem estruturas. Como mostra Legris, para Peirce a função de um ícone é “tornar visível (ou 'visualizar') a estrutura do raciocínio" (2012, p. 9, tradução nossa); ideia corroborada por Franco e Borges (2016), as quais ressaltam que - para Peirce diagramas não necessariamente se assemelham aos seus objetos em um sentido de "aparência”, mas sim para com as relações entre as partes daquilo que representam.

Essa noção, a qual será tratada aqui como "semelhança estrutural”, está presente em uma vasta gama de estudos realizados na área, sendo um ponto de unanimidade por parte de vários autores, embora utilizem nomenclaturas diferentes para se referir à mesma noção. Como ressalva Sato (2013), dentre as variadas maneiras que essa ideia aparece, encontramos as nomenclaturas de "semelhança estrutural", "correspondência estrutural", "relações de correspondência”, “isomorfismos”, etc. Mancosu (2012), por exemplo, utiliza a ideia de "forma de representação", efetuando uma analogia entre a forma como diagramas representam e a noção wittgensteiniana de figuração. Por uma nomenclatura ou por outra, parece estar acertada a ideia de que diagramas se distinguem de métodos sentenciais enquanto ferramentas de representação por utilizarem aspectos que preservam alguma parte das estruturas ou relações daquilo que representam.

relações de tipo b), visto que diagramas podem trabalhar com objetos e relações muito mais familiares para os sujeitos do que são as fórmulas de um sistema algébrico. 


\section{UTILIZAÇÃO DO PANO DE FUNDO E ELEMENTOS ACIDENTAIS}

Embora haja um certo consenso sobre a maneira como diagramas representam, em termos de preservação de estrutura e abstração das entidades / objetos envolvidos, não há a mesma unanimidade sobre como isso ocorre. Como argumentamos (2015), a maneira como diagramas representam as relações entre os objetos é determinada pelos aspectos espaciais do "pano de fundo"; nesse sentido, certas partes e propriedades do modo como o espaço é utilizado para construir os diagramas possuem funções relevantes na representação e na manipulação das informações visadas. Nos métodos sentenciais, esse espaço não possui uma função nesse sentido. Nesses últimos, a alocação espacial dos signos é permeada apenas pela concatenação, pela função de ordenamento e pela adição de marcadores, como o espaçamento entre letras e fórmulas; enquanto nos primeiros, o pano de fundo do diagrama desempenha uma ou mais funções sintáticas. ${ }^{5}$ Assim, nos sistemas puramente sentenciais, todas as funções sintáticas são desempenhadas através da representação alocada em caracteres simbólicos.

É com base nisso que Shin (1994) afirma que diagramas utilizam menos convenções, pois não necessitam "de um dispositivo sintático extra ou qualquer convenção para essa relação" (SHIN, 1994, p. 161, tradução nossa). No entanto, como já afirmamos, a própria adaptação é efetuada em um contexto convencional. Assim, para os contextos lógicos, a utilização de diagramas só pode ser menos convencional se estivermos considerando que os indivíduos já estão familiarizados ou inseridos no contexto de interpretação do diagrama, o que proporciona resultados para as análises da relação que mencionamos como de tipo b). Um exemplo dessa abordagem pode ser encontrado em Sato (2013), o qual desenvolve experimentos sobre como indivíduos manipulam diagramas de acordo com aquilo que já lhes é familiar.

Dessa forma, métodos puramente sentenciais são distintos de métodos diagramáticos por conta do modo como trabalham a manipulação das informações que denotam em detrimento da utilização de aspectos espaciais. Tal como apresentado por nós em outro

\footnotetext{
${ }^{5}$ A distinção entre como isso ocorre em ambos os meios é estritamente necessária. O fato de as representações sentenciais utilizarem o "pano de fundo", mesmo que de maneira tácita, é um dos pontos para Peirce considerar que elas possuem elementos diagramáticos. Para o autor, a amplitude do conceito de "diagrama" abarca os signos dotados de estrutura, de forma com que a organização sintática da linguagem escrita esteja incluída nessa categoria. Todavia, há uma diferença entre funções sintáticas em termos de organização por "espelho" da linguagem falada, de organização puramente convencional e de desempenhar um papel central nos métodos de cálculo e raciocínio. Por exemplo, a representação para os cálculos de matrizes, organizadas em linhas e colunas, desempenha um papel heurístico adicional do que a simples concatenação e separação de símbolos, pois organiza os aspectos espaciais, do "pano de fundo", de acordo com regras que são diretamente utilizadas no procedimento de cálculo.
} 
momento (2015), isso exige que ambos tenham regras de manipulação distintas: diagramas, enquanto métodos, devem deixar explícitas diretrizes sobre como utilizar o pano fundo espacial. Como não poderia deixar de ser, as representações sentenciais obtêm os prejuízos e os lucros representacionais de disporem de símbolos para representar as operações sintáticas, enquanto as representações diagramáticas obtêm os lucros e os prejuízos de converter algumas dessas operações em relações espaciais, topológicas, ou qualquer outra utilização do pano de fundo. Portanto, se há algo que torne diagramas menos seguros, menos rigorosos, menos claros, ou com potencial errôneo incontornável, esse algo deriva diretamente dessa característica.

Conforme argumentam Barwise e Etchemendy (1996) para o contexto da lógica, mas também Lassalle Casanave, Schultz e Vaz (2009) para a matemática, as próprias noções de "demonstração", "fórmula bem formada" e "prova formal" excluem, por definição, qualquer possibilidade de figuras e diagramas serem partes das mesmas. Para os autores, a principal razão para a má reputação dessas ferramentas nas ciências formais deriva da ideia de que elas possuem aspectos acidentais que as tornariam potencialmente enganosas. De modo semelhante, Azzouni (2013) argumenta que esses potenciais enganosos teriam sido vistos como as justificativas para a ideia de que tais ferramentas comprometeriam o rigor necessário para o desenvolvimento dos estudos formais.

Esses aspectos são bem conhecidos na literatura por conta da distinção efetuada por Manders (2008) entre elementos "exatos" e elementos "coexatos". Os aspectos "exatos" são caracterizados por elementos sensíveis às deformações diagramáticas, mas que não atuam de forma relevante no modo como o diagrama representa. Já os aspectos "coexatos" são caracterizados pelos elementos que não são sensíveis às deformações, sendo estes os que podem serem utilizados para as representações diagramáticas terem sucesso. Estes últimos devem estar em conformidade com o propósito pelo qual o diagrama foi construído, pois devem estar alocados de modo com que sejam "exemplos de relações que são mostradas pelo diagrama em qualquer diagramação adequada, sendo, portanto, informações que podem ser lidas ou extraídas legitimamente do diagrama" (LASSALLE CASANAVE; SCHULTZ; VAZ, 2009, p. 18). Nesse sentido, os aspectos exatos e coexatos de métodos diagramáticos em contextos lógicos variam de acordo com o que o método utiliza, de acordo com o background, com os aspectos convencionais. Por exemplo, Sato (2013, p. 104) fornece um diagrama para a representação de afirmações prováveis que utiliza relações de proporção entre figuras fechadas. Nesse caso, o tamanho de uma figura é um aspecto "coexato", pois quanto maior a 
região delimitada no diagrama, maior a probabilidade da informação que ele representa. Em outros contextos, como nos diagramas de Venn, o tamanho das figuras são aspectos "exatos", visto que são irrelevantes.

A distinção proposta por Manders (2008) é importante pois a ideia de que diagramas são enganosos tem por base a exigência de certas características diagramáticas. Todavia, essa exigência só é plausível quando pautada pelos elementos que são relevantes para a diagramação. Uma vez que todos os elementos relevantes podem serem elementos "coexatos", o potencial errôneo que torna métodos diagramáticos menos rigorosos é contornado. Ademais, o propósito de qualquer método deve ser levado em conta, de modo que exigir que uma figura seja de uma forma ou outra por conta do rigor pode ser análogo à exigir que se use uma determinada fonte, com um determinado tamanho, com uma determinada quantidade de caracteres, em uma demonstração sentencial; ou seja, ter foco em um elemento irrelevante para o que está sendo representado.

Enquanto a discussão em contextos lógicos é abarcada pelo fato de que um diagrama deve estar inserido em um contexto de representação, em geometria plana a solução parece ser um pouco mais difícil. Como argumenta Azzouni (2013), os aspectos exatos dos desenhos de figuras geométricas são suas deformações físicas, porém, toda inscrição física realizada, toda figura desenhada é acompanhada por um determinado aspecto. Por exemplo, o desenho de um triângulo espelha sempre um triângulo particular, e isso possui duas consequências. Por um lado, em detrimento disso poderia haver uma exigência de que os diagramas geométricos, os desenhos das figuras, sejam vistos como instâncias físicas dos conceitos que representam. Porém, essa exigência não faz sentido, visto que o que é objeto da geometria foi radicalmente separado de qualquer instância física pela abstração dos conceitos, como por exemplo o conceito de triângulo, de segmento de reta, de ponto, etc. Há, portanto, uma discussão ontológica de suma importância nesse ponto, através da qual se assumirá uma ou outra resposta para o problema, mas que provavelmente será compatível com o que fora afirmado por Manders (2008).

Por outro lado, dada essa mesma separação, há uma tentativa de afirmar que como o mundo físico é composto por instâncias únicas, um diagrama ou um desenho não pode ser entendido como uma representação geral. Nesse sentido, a instância física da figura de um triângulo não poderia compor parte em uma demonstração por não representar todos os 
triângulos relevantes para a demonstração. ${ }^{6}$ Como argumenta Azzouni (2013), essa ideia defende apenas que a utilização de figuras compromete a amplitude de casos abarcados, mas não o rigor da demonstração em questão. $\mathrm{O}$ autor complementa essa reflexão afirmando que "provas" diagramáticas possuem sempre um escopo limitado.

Contudo, tendo em vista que a utilização de representações diagramáticas em lógica requer uma sensibilidade para com o contexto no qual o diagrama está inserido, é possível questionar se o mesmo não ocorre com os contextos geométricos. Em lógica, diagramas podem figurar como representações gerais; possuir partes que representam a extensão de termos gerais, do conteúdo de uma proposição, bem como dispor de meios para adaptar as quantificações universais. Esses aspectos em torno do que cada parte do diagrama significa para o contexto lógico deriva da simples adaptação deles, visto que suas construções são primordialmente idealizações dos conteúdos. No que isso difere nos casos geométricos? Não poderia ser o caso de que, por exemplo, a figura de um triângulo seja uma idealização enquanto representação do conceito de triângulo, que os seus aspectos físicos estejam no mesmo nível dos que a palavra "triângulo" possui? Aparentemente, o maior problema para essa sugestão é a dificuldade de mostrar o que resta enquanto elemento "coexato" se entendermos as figuras dessa forma. ${ }^{7}$

Voltando para o contexto lógico, a enunciação de aspectos "exatos" e "coexatos" em detrimento de como os diagramas se adequam aos propósitos pelo qual o método fora construído parece estar acertada. É nessa via que estudos recentes buscam eliminar os aspectos que não são relevantes nos métodos, tornando explícitas as regras de construção, manipulação e que permitem inferências legítimas através dos diagramas. Um exemplo dessas investigações é o estudo ofertado por Hammer (2001) sobre a funcionalidade dos métodos diagramáticos de Venn e de Peirce. Enquanto as regras e diretrizes de construção de um método diagramático são explicitadas, os elementos "exatos" que poderiam distorcer a interpretação e conduzir manipulações errôneas são evitados. Quando tais aspectos deixam de ter a explicitação necessária por se tornarem conteúdos tácitos para os sujeitos, faz sentido pensar que métodos diagramáticos são menos convencionais, do modo como Shin (1994) os caracteriza. Conjetura-se, portanto, que os defeitos da falta de rigor e clareza atribuídos aos

\footnotetext{
${ }^{6}$ Ambos os aspectos remetem às discussões ontológicas envolvidas no clássico debate entre realistas e idealistas sobre o status metafísico das entidades matemáticas. Um breve resumo desse assunto pode ser encontrado em Mancosu (2012), o qual compara as posições platônicas e as que seguem a ideia do bispo Berkeley.

${ }^{7}$ Por envolver as especificidades da geometria, bem como os diversos comprometimentos ontológicos acerca das entidades matemáticas, esse assunto merece ser explorado em um artigo próprio.
} 
métodos diagramáticos possuem origem na prática de tomar esse mesmo conteúdo como algo tácito sem o devido cuidado - o que não ocorre nas representações sentenciais visto que para estas, como argumentam Barwise e Etchemendy (1996), houve um enorme esforço intelectual a fim de explicitar os elementos necessários para as tornar meios de cálculos e raciocínios rigorosos. $^{8}$

\section{CONSEQUÊNCIAS REPRESENTACIONAIS}

Análises como as efetuadas por Hammer (2001) e outros autores, retomam as ferramentas diagramáticas enquanto partes em métodos de decisão, enquanto métodos heterogêneos, obtendo resultados interessantes. Tais resultados compõem distinções necessárias para a compreensão do que é um método diagramático, bem como consequências representacionais advindas da comparação entre distintos métodos diagramáticos. Ambos fortalecem a ideia de que diagramas não possuem um caráter errôneo intrínseco ou incontornável, além de explorarem questões sobre suas funcionalidades e capacidades expressivas. Ademais, essas abordagens fornecem um estudo em prol da segurança dos métodos analisados, pois tornam explícitas as regras de construção e manipulação dos diagramas analisados, eliminando caso a caso os aspectos acidentais.

Esse tipo de estudo se enquadra nas abordagens semióticas de tipo a), porém possui um viés mais técnico e específico. Hammer (2001) e Shimojima (1996) enunciam uma diferença entre questões lógicas do ponto de vista diagramático, enquanto operações físicas, e questões psicológicas e cognitivas de modo correlato ao que está diferenciado aqui entre abordagens de tipo a) e tipo b), respectivamente. Tratando dos resultados dessas abordagens de tipo a), é importante salientar inicialmente que um método diagramático é composto por certas partes essenciais. O diagrama apresentado na Figura 2 serve de guia para as considerações que seguem.

\footnotetext{
${ }^{8}$ A ideia de "conteúdo tácito" presente aqui está sendo utilizada do mesmo modo como efetuado por Azzouni (2013).
} 


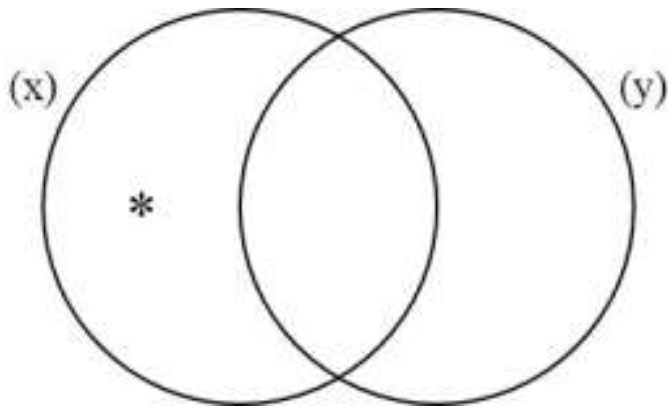

Figura 2. Diagrama com interseção entre figuras fechadas e marcação em uma região

Em primeiro lugar, assim como há uma explicitação dos signos primitivos, do que são fórmulas, fórmulas bem formadas, e demais elementos "pré-teóricos" de um sistema formal, no caso dos métodos diagramáticos isso também deve ocorrer. Por exemplo, deve constar no background do método que ele é composto por certos elementos representativos, no caso do Diagrama da Figura 2, que ele é composto por figuras fechadas e admite marcações em regiões com o símbolo “*”. O detalhamento desses objetos é acompanhado de uma descrição dos elementos mais básicos do método diagramático, daqueles elementos que assim que os indivíduos apreendem, tornam-se aspectos tácitos. Isso constitui uma analogia com o que fazemos em métodos sentenciais ao determinar as fórmulas bem formadas.

Uma explicitação um pouco diferente ocorre para o conjunto de regras que guiam os procedimentos operacionais do método diagramático: que uma região no diagrama admite uma e apenas uma marcação, que as figuras fechadas podem ou devem formar intersecções, que há um número limitado de figuras fechadas possíveis para o método funcionar, etc. Por analogia, essa etapa consiste em um processo semelhante ao fornecimento de axiomas para as relações nos sistemas formais.

Por fim, é preciso salientar um último elemento que difere um pouco dos primeiros: é necessário que esteja explícita uma regra para identificar resultados legítimos e ilegítimos. Essa regra, para os casos mais comuns na literatura sobre diagramas em lógica, os quais são aplicados para a lógica silogística, é geralmente descrita como a maneira pela qual pode-se encontrar uma conclusão a partir da representação das premissas, a qual para o funcionamento de diagramas baseados em regiões é usualmente encontrada na literatura da área como "uma conclusão se segue de um conjunto de premissas se todas as maneiras em que diagramamos as premissas resultam em um diagrama que representa a conclusão" (LEMON; PRATT, 1998, p. 
575, tradução nossa). ${ }^{9}$ A forma como essa última regra é encontrada, no entanto, destoa do caráter dos componentes anteriores que foram citados. Ocorre que aqueles não fazem menções aos significados dos objetos e de suas relações, enquanto a diretriz para encontrar uma conclusão pressupõe a analogia entre o diagrama e o sistema lógico. Grosso modo, isso enuncia uma distinção correlata entre elementos "semânticos" e "sintáticos", nos quais a lógica objeto do diagrama seria um "modelo semântico" do método diagramático. ${ }^{10}$ Portanto, é apenas após saber a qual lógica e suas sequências de fórmulas válidas que pode-se atestar a validade de uma conclusão em um método diagramático de acordo com a regra citada.

Assim, ao contrário do que defendemos anteriormente (2015), um método diagramático não pode visar sozinho o mesmo conjunto de alvos dos sistemas lógicos. Diagramas perpassam métodos sentenciais e só se se dirigem a alvos lógicos por conta de uma relação com os mesmos através de seus resultados. Isso é evidenciado através desse tipo de regra para uma derivação válida em um sistema diagramático, que é necessária para identificar resultados legítimos e ilegítimos, porque ela precisa ser coordenada com os sistemas lógicos aos quais os métodos estão relacionados. Nesse sentido, configurações diagramáticas são válidas se encontramos um modo de estabelecer a sua "validade interna" ao método diagramático por referência às formas válidas conhecidas e derivadas em sistemas lógicos sentenciais, sejam eles tradicionais, clássicos ou não clássicos. Quando há resultados incompatíveis em um mesmo âmbito de aplicação, como por exemplo o que realizamos noutro estudo (2015), haverá uma tarefa em torno de coordenar esses resultados e encontrar os seus significados. Nesse sentido, é possível que diagramas fomentem descobertas para um âmbito lógico, ou forneçam apoio para teses em filosofia da lógica. Porém, eles exigem um tratamento cauteloso nesse sentido, visto que é mais provável, ou menos raro, que o método esteja pouco preciso e que suas regras não estejam devidamente ajustadas, conduzindo conclusões que não deveriam se seguir.

\footnotetext{
${ }^{9}$ Uma versão similar e simplificada dessas etapas está desenvolvida em A variedade dos métodos diagramáticos a partir da perspectiva da silogística (2015).

${ }^{10}$ Os termos "semântica" e "sintaxe" são apenas versões correlatas e aproximadas do significado que eles geralmente possuem por conta de seu uso em análises de linguística. O mesmo ocorre para termos que possuem origem em lógica e matemática, como "correção", que aparecerá no decorrer do artigo. Ocorre que, por estarem transpostos para contextos diagramáticos, eles demandam um certo cuidado. Por conta disso, utilizam-se aspas para deixar claro que seus significados dependem dessa aproximação entre os contextos, supondo que a mesma é possível e legítima. Dessa forma, a "sintaxe" aqui diz respeito ao conjunto de regras e princípios combinatórios e operacionais que regem os métodos diagramáticos, enquanto a "semântica" é vista como as regras que traduzem esses métodos em termos lógicos, como eles se referem aos objetos de seu domínio de alvo.
} 
Cabe notar também que em certos métodos diagramáticos, em especial nos diagramas baseados em regiões delimitadas por combinações de figuras fechadas como os diagramas de Euler, Venn e Carroll para a silogística, a diagramação correspondente à informação das premissas de um argumento válido contém a informação correspondente da conclusão do argumento. Esse elemento é o foco da abordagem de Shimojima (1996) em torno do que o autor denominou "free ride". Segundo o autor, essa característica decorre das limitações espaciais que determinam essa forma de representação, possibilitando que o resultado de uma inferência válida esteja no diagrama sem haver uma regra ou diretriz que comande passos para representar essa informação. Tais limitações espaciais correspondem ao modo como o método diagramático preserva uma "semelhança estrutural" com os conteúdos que ele está representando. Shimojima (1996) salienta ainda que um "free ride" é a obtenção de uma informação "semanticamente" relevante no diagrama, sem haver instruções operacionais que dirijam explicitamente a representação dessa informação. Há, portanto, a ressalva da distinção entre aspectos "semânticos" e operacionais de modo semelhante ao que fora argumentado aqui.

Todavia, é possível caracterizar a regra para derivações válidas em um método diagramático sem fazer menção ao domínio "semântico" do método diagramático, embora a literatura da área não tenha o costume de fazê-lo, por já tratar essa ferramenta de acordo com a sua aplicação. Um exemplo desses são os diagramas baseados em grafos, como por exemplo os "Dígrafos de Gardner" apresentados por Sautter (2013) também para a silogística, os quais explicitam dentre as combinações diagramáticas possíveis aquelas que são legítimas através do método (algo que pode ser análogo a uma "axiomática" dos diagramas), obtendo regras para identificar e construir resultados legítimos (procedimento semelhante ao que ocorre com fórmulas derivadas enquanto teoremas em métodos formais).

De qualquer modo, a utilidade dos diagramas só existe quando exposta essas contrapartes "semânticas", as quais exigem a explicitação de regras de tradução dos signos e das relações espaciais relevantes do método. Nesse caso, um método diagramático pode ser visto como um jogo de peças, tal como um quebra-cabeça, que pode ser aplicado a diferentes domínios, ou seja, que pode conter diferentes modelos, admitindo uma pluralidade de 
adaptações. Por exemplo, o diagrama apresentado na Figura 2 pode ser compreendido de pelo menos oito maneiras diferentes. ${ }^{11}$

A culminância desses fatores resulta nos elementos suficientes para caracterizar e compreender o funcionamento de um método diagramático, suas virtudes e consequências representacionais. Tal como Azzouni (2013) e Shimojima (1996) argumentam, representações desse tipo possuem limites expressivos que devem ser respeitados. Sobre esses, a literatura da área tem tratado de mostrar através dos estudos de casos o que cada tipo método diagramático possui como limitação expressiva. Visto que é possível separar aqueles aspectos operacionais e "sintáticos" dos métodos, dos aspectos que os traduzem para os contextos lógicos (que constituem as diretrizes para a correta aplicação deles a uma lógica específica), pode ocorrer que haja uma variedade de métodos aplicáveis para o mesmo sistema lógico, como ocorre com a silogística. Tal como pensado acima, haverá uma coordenação entre método diagramático e sistema lógico sentencial e, se isso estiver correto, poderemos possuir uma aplicação também no sentido inverso, que as contrapartes "sintáticas" de um mesmo método seja coordenada para dois ou mais sistemas lógicos (um clássico e um não clássico, por exemplo), diferindo apenas na regra de derivação do ponto de vista "semântico".

Dessa forma, diferentes métodos diagramáticos, por trabalharem com diferentes formas de "semelhança estrutural" (como por exemplo entre intersecções de figuras fechadas e relações de pertinência entre conjuntos, como ocorre em diagramas de Venn e de Carroll, ou entre comprimentos de segmentos de retas paralelos e relações de pertinência - caso dos diagramas de Leibniz), administram distintas aplicabilidades representacionais, com virtudes e prejuízos em torno de suas limitações expressivas e operacionais - que variam em um nível entre os tipos de diagramas e em outro nível de método diagramático para método diagramático. Cabe notar, porém, que essas limitações são afirmadas desde uma perspectiva que mescla aspectos das relações semióticas de tipo a) e de tipo b). Abrindo um parêntese explicativo para esse ponto, um exemplo que ilustra tal afirmação pode ser encontrado em Englebretsen (1992). O autor argumenta que há uma restrição que impede diagramas baseados em regiões de representarem adequadamente silogismos com mais de três termos, mas que o mesmo não ocorre para os diagramas lineares. Haveria, portanto, uma limitação expressiva para o primeiro tipo de diagrama, para a qual os do segundo tipo possuiriam maior

\footnotetext{
${ }^{11}$ Para tal, basta considerar que as figuras denotam termos da silogística ou proposições da lógica clássica, que a abordagem pré-estabelecida seja extensional ou intensional e que a marcação possua um aspecto positivo ou negativo da relação estabelecida na região demarcada, formando oito combinações possíveis.
} 
aplicabilidade expressiva. Todavia, Sautter (2010) ressalta que diagramas baseados em figuras fechadas e regiões podem representar silogismos com cinco termos se realizadas as devidas adaptações, embora isso acompanhe certas dificuldades práticas. A Figura 3 apresenta a adaptação dos diagramas de Venn para cinco termos tal como ilustrado por Sautter (2010).

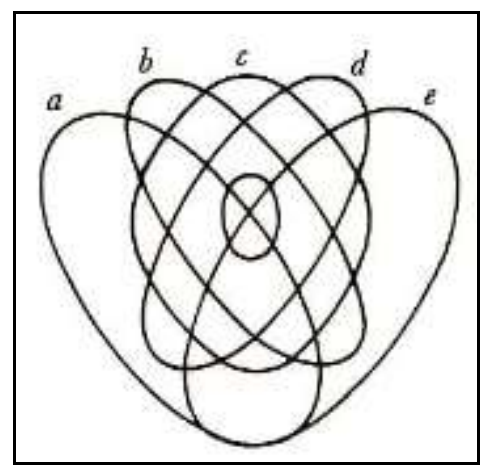

Figura 3. Diagrama de Venn para cinco termos apresentado por Sautter (2010)

Há, certamente, mais de uma maneira diagramática de representar um silogismo com cinco termos através de diagramas similares aos de Venn. O modo apresentado por Sautter (2010), ilustrado na Figura 3, utiliza uma figura fechada de topologia distinta das demais, demarcada por "c", para que seja possível encontramos todas as combinações necessárias entre os termos representados. Nesse sentido, a restrição afirmada por Englebretsen (1992) só pode existir em um nível não técnico-teórico, mas prático. Do ponto de vista prático, pode-se estar em jogo tanto uma dificuldade em torno da construção e da manipulação do diagrama, podendo ter um número diferente de regras operacionais, quanto dos elementos psicológicos e cognitivos envolvidos na utilização da ferramenta, como a visualização e a atenção requerida pelos usuários, que defasam o caráter e a utilidade heurística delas. Sobre esse último ponto, como afirmam Lemon e Pratt "o problema parece ser que, quando sistemas diagramáticos são utilizados para representar um grande número de premissas, o resultado tende a parecer como um prato de espaguete" (1998, p. 576, tradução nossa). ${ }^{12}$

É importante perceber como ambas as dificuldades compõem aspectos das relações semióticas de tipo b), visto que retomam o problema das representações diagramáticas em detrimento dos processos cognitivos dos indivíduos que as utilizam. Uma descrição dessas dificuldades é oferecida por Abeles (2007), a qual distingue duas virtudes dos métodos

\footnotetext{
${ }^{12}$ Isso significa que a utilidade dos sistemas diagramáticos é também condicionada pelo modo como o sistema administra a "semelhança estrutural" com aquilo que ele visa representar.
} 
diagramáticos: a facilidade de diagramação (easy of drawing) e a clareza visual (visual clarity). A denominação utilizada pela autora faz com que essas noções sejam autoexplicativas. ${ }^{13}$ Porém, tais características estão relacionadas às virtudes da utilização das ferramentas diagramáticas, por conta de seu caráter heurístico, não sendo restrições teóricas ou constituindo elementos que as impeçam de serem rigorosas.

Nesse sentido, é imprescindível distinguir consequências representacionais de um ponto de vista das relações entre o conjunto de signos representantes e os objetos representados, do ponto de vista das relações entre os aspectos psicológicos e cognitivos dos quais decorrem as virtudes de suas utilidades. Afinal, o rigor de um método puramente sentencial não é afetado pela facilidade com a qual manipulamos símbolos ou visualizamos fórmulas, embora seja importante mostrar que no caso das ferramentas diagramáticas, a sua utilidade enquanto ferramentas heurísticas não decorre em virtude exclusiva dos aspectos “coexatos" delas.

Realizada essa ressalva, podemos retomar os limites expressivos e problemas operacionais desde um ponto de vista sobre a funcionalidade dos métodos diagramáticos. $\mathrm{O}$ recurso aos aspectos espaciais que caracterizam os métodos diagramáticos e os distinguem de métodos sentenciais podem exigir que sejam feitas restrições operacionais de forma explícita para evitar que haja configurações legítimas do ponto de vista "sintático", ou seja, das regras do método diagramático, mas que não são legítimas do ponto de vista "semântico", da lógica para o qual o método foi construído. Exemplos disso são encontrados nos diagramas lineares apresentados por Englebretsen (1992) e nos diagramas lineares de Leibniz, ambos para a silogística, os quais necessitam de regras adicionais para impedir que algumas configurações diagramáticas que expressam premissas particulares esbocem, através da regra supracitada e pelo conceito de "free ride", informações que seriam interpretadas como conclusões de um raciocínio válido. ${ }^{14}$ Outro exemplo de limitação expressiva decorre da exigência para métodos baseados em regiões, como os diagramas de Venn e de Carroll para a silogística, da informação de uma premissa particular ser sempre precedida pela representação da informação de uma premissa universal, caso contrário o método não funcionará corretamente.

\footnotetext{
${ }^{13}$ Sautter (2010) também explora essas noções e oferece um excelente exemplo para ilustrar a segunda, a clareza visual, através de um "problema de vizinhança" em um puzzle no jogo de xadrez envolvendo o movimento das peças de cavalo e as casas disponíveis.

${ }^{14}$ Visto que tais métodos visam a silogística como "modelo", que a colocam como contraparte "semântica", isso indica que os métodos não são "corretos" (soundness), ou seja, que por analogia com o que ocorre nos sistemas formais, as contrapartes diagramáticas análogas aos elementos "sintáticos" não correspondem aos elementos "semânticos" que foram estipulados para os diagramas.
} 
Sobre a origem desses limites expressivos das ferramentas diagramáticas, a fixação de uma função sintática em um elemento espacial a fim de obter uma representação que preserve em algum aspecto de sua estrutura espacial uma relação entre os objetos representados determina o sucesso de cada método. Para além dos contextos lógicos, representações de estilo diagramático, como mapas e calendários, evidenciam esse aspecto. Tomando um mapa como exemplo, nessa forma de representação preservam-se relações espaciais dos lugares representados através de relações espaciais do "pano de fundo", de forma com que referir-se a um objeto que não esteja alocado espacialmente seja uma tarefa que depende de um dispositivo simbólico extra, acompanhado de uma legenda que o explique. Isso ocorre porque, assim como nos diagramas, nos mapas as informações que podem ser representadas são condicionadas pelo meio como esses trabalham seus dispositivos representacionais em detrimento do papel que fora estipulado para o "pano de fundo". ${ }^{15}$ Uma consequência mais geral dessa limitação é a incapacidade de métodos diagramáticos conterem informações de segunda ordem, serem metalinguísticos. É por esse motivo que métodos diagramáticos são sempre heterogêneos, pois necessitam de uma espécie de legenda, que será linguística, sobre suas regras operacionais e como devemos traduzi-los em termos lógicos.

Esses elementos evidenciam a importância dos estudos sobre o funcionamento dos métodos diagramáticos, caso a caso. É apenas na linha desses trabalhos que os elementos acidentais envolvidos nos métodos diagramáticos são evidenciados e diagnosticados como incontornáveis ou irrelevantes. Há sim, nos contextos lógicos, elementos que conduzem a raciocínios enganosos, como os que foram ressaltados no parágrafo anterior. Todavia, tal como Barwise e Etchemendy (1996) argumentaram, tais características acidentais não são intrínsecas aos métodos diagramáticos, nem muito distante do que também ocorreu em métodos sentencias, de forma que podemos manter um otimismo frente aos projetos de estudo dessas ferramentas. Ainda assim, ao contrário do que é levantado em A variedade dos métodos diagramáticos a partir da perspectiva da silogística (2015), isso só é possível em um

\footnotetext{
${ }^{15}$ Ilustrando essas afirmações, imaginemos que um mapa que represente ruas, avenidas e edificações de uma cidade também tenha o propósito de referir monumentos históricos que foram demolidos. Para esses, haverá um dispositivo simbólico que deixará claro quais são esses monumentos, diferenciando-os das edificações atuais da cidade, como por exemplo uma marcação, estilo ou cor diferente para esses símbolos, junto de uma legenda que as explique. Outro exemplo pode ser visualizado na intenção de representar informações vagas sobre a cidade como, por exemplo que em uma rua qualquer existem duas igrejas. Como todas as representações são diretamente alocadas no que denominados de "pano de fundo", as referências às igrejas serão sempre inseridas em um ambiente que possui a função de alocar espacialmente os objetos; assim, o mapa deverá conter uma outra região claramente construída para esse tipo de informação ou um dispositivo simbólico para tal.
} 
ambiente de correlação entre sistema formal e sistema diagramático que evidencie os significados da existência de resultados incompatíveis entre eles, quando houver.

\section{CONSIDERAÇÕES FINAIS}

O presente artigo teve por objetivo analisar como representações diagramáticas se distinguem de representações sentenciais em contextos lógicos, e o que isso significa frente às virtudes de clareza, rigor e vagueza. Argumentou-se que diagramas representam explorando relações espaciais em partes de seu "pano de fundo", o que proporciona uma relação de semelhança estrutural para com alguma relação do conjunto de objetos que representam. Como cada método administra essa característica ao seu modo, embora existam semelhanças topológicas entre eles que nos permitam falar em tipos de diagramas (diagramas lineares; baseados em regiões de figuras fechadas; baseados em grafos, entre outros), torna-se necessário o estudo de casos para verificar as características representacionais de cada um. De um ponto de vista geral, no entanto, não parece haver justificativas para considerar sistemas diagramáticos como menos rigorosos, visto que os aspectos acidentais recaem no mais das vezes em elementos irrelevantes. Portanto, os estudos em prol da "rigorização" dessas ferramentas perpassam a tarefa de evidenciar os elementos "coexatos" dos métodos diagramáticos, tornando-os explícitos, mostrando como eles são parte principal dos frutos de sua utilidade, de seu caráter heurístico/pedagógico e coordenando-os com sistemas não diagramáticos com um mesmo domínio de alvos.

\section{REFERÊNCIAS}

ABELES, Francine. Lewis Carroll's Visual Logic. History and Philosophy of Logic, v. 28, n 1, p. 1-17, 2007.

AZZOUNI, Jody. That we see that some diagrammatic proofs are perfectly rigorous.

Philosophia Mathematica, v. 21, n 3, p. 323-338, 2013.

BARWISE, Jon.; ETCHEMENDY, John. Visual information and valid reasoning. In:

ALLWEIN, Gerard; BARWISE, Jon (eds). Logical reasoning with diagrams. New York:

Oxford University Press, 1996. p. 3-26.

ENGLEBRETSEN, George. Linear diagrams for syllogisms (with relationals). Notre Dame Journal of Formal Logic, v. 33, n. 1, p. 31-69, 1992. 
FRANCO, Juliana; BORGES, Priscila. O conceito de diagrama em Peirce: uma leitura semiótica para além da gramática especulativa. Cognitio, v. 14, n. 1, p.45-54, jan./jun. 2016.

GIAQUINTO, Marcus. Visualizing in mathematics. In: MANCOSU, Paolo (ed.). The philosophy of mathematical practice. Oxford: Oxford University Press, 2008. p. 22-64.

GIARDINO, Valeria. A practice-based approach to diagrams. In: MOKTEFI, Amirouche; SHIN, Sun-Joo (eds.). Visual reasoning with diagrams. Basel: Birkhäuser, 2013. p. 135152.

HAMMER, Eric. Diagrammatic logic. In: GABBAY, Dov; GUENTHNER, Franz (eds). Handbook of philosophical logic. 2. ed. vol. 4. Dordrecht: Springer, 2001. p. 395-422.

LASSALLE CASANAVE, Abel; VAZ, Bruno; SCHULTZ, Sérgio. Diagramas e provas. Dois Pontos, v. 6, n. 2, p. 13-25, 2009.

LEGRIS, Javier. Conocimiento gráfico y diagramas desde la perspectiva de C. S. Peirce. In: ESQUISABEL, Oscar; SAUTTER, Frank (Ed.). Conocimiento simbólico y conocimiento gráfico: historia y teoría. Buenos Aires: Academia Nacional de Ciencias de Buenos Aires, 2013. p. 51-60.

LEMON, Oliver; PRATT, Ian. On the insufficiency of linear diagrams for syllogisms. Notre Dame Journal of Formal Logic, v. 39, n. 4, p. 573-580, 1998.

MANCOSU, Paolo. Introduction. In: MANCOSU, Paolo. The philosofy of mathematical practice. Oxford: Oxford University Press, 2008. p. 1-21.

MANCOSU, Paolo. O visível e o invisível. In: LASSALLE CASANAVE, Abel; SAUTTER, Frank (eds). Filosofia contemporânea e história da filosofia: visualização nas ciências formais. London: College Publications, 2012. p. 1-32.

MANCOSU, Paolo. Visualization in Logic and Mathematics. In: MANCOSU, Paolo; JØRGENSEN, Klaus; PEDERSEN, Stig (eds). Visualization, explanation and reasoning styles in mathematics. Dordrecht: Springer, 2005. p. 13-30.

MANDERS, Kenneth. Diagram-based geometric practice. In: MANCOSU, Paolo (ed.). The philosophy of mathematical practice. Oxford: Oxford University Press, 2008. p. 65-79.

PI NHEIRO, Félix Flores. A variedade dos métodos diagramáticos a partir da perspectiva da silogística. Dissertação [mestrado]. Santa Maria: UFSM, 2015. Disponível em: http://w3.ufsm.br/ppgf/wp-content/uploads/2011/10/F\%C3\%A9lix-Pinheiro.pdf.

SATO, Yuri. The cognitve efficacy of diagrammatic representations in logic reasoning. 148 p. Tese [Doutorado em Filosofia]. The Graduate School of of Letters, Keio University, Minato - Tokyo, 2013.

SAUTTER, Frank. A funcionalidade dos métodos diagramáticos. Representaciones, v. 6, p. 61-73, 2010. 
SAUTTER, Frank. Método de Gardner para a silogística. Cognitio, v. 14, n. 2, p. 221-234, 2013.

SEOANE, José. Definición y visualización. Notae Philosophicae Scientiae Formalis, vol. 1, n. 2, p. 160-173, out. 2012.

SHIMOJIMA, Atsushi. Operational constraints in diagrammatic reasoning. In: ALLWEIN, Gerard; BARWISE, Jon (eds). Logical reasoning with diagrams. New York: Oxford University Press, 1996. p. 27-49.

SHIN, Sun-Joo. The logical Status of diagrams. New York: Cambridge university press, 1994.

SUNDHOLM, Göran. Questions of Proof. Manuscrito, v. 16, n. 2, p. 47-70, 1993. 